\title{
A Study on the Influence of Learning Motivation on Learning Engagement of Chinese Immersion Primary School Students in the United States
}

\author{
Sijun $\mathrm{Li}^{1, *}$ \\ ${ }^{1}$ School of Foreign Languages, Yunnan Normal University, Kunming City, Yunnan, 650500, China
*Corresponding author. Email: 156422904@qq.com
}

\begin{abstract}
This study investigates the learning motivation and learning engagement of Chinese immersion primary school students in Minnesota, USA. According to the statistical data of questionnaire survey and model construction, it is shown that both internal motivation and external motivation have a direct positive impact on learning engagement; learning motivation and learning participation will not directly affect students' academic achievement. Based on this study, the learning templates suitable for international conditions and with Chinese characteristics are summarized, and the immersion Chinese innovative teaching and learning mode is proposed.
\end{abstract}

Keywords: Chinese immersion, learning motivation, learning engagement

\section{INTRODUCTION}

The immersion program, also known as bilingual teaching or bilingual education, is explained in Longman Dictionary of Language Teaching and Applied Linguistics as "using a second language or foreign language to teach knowledge subjects in schools". [1] Johnson \& Swain pointed out that "immersion" teaching means that bilingual teachers use the second language which students want to learn as the medium of instruction, and the courses they learn are the same as those in the mother tongue mediated class. [2] Compared with the traditional teaching mode, immersion teaching enables students to communicate in the context of using the second language, and the language level is improved sufficiently in the target language environment. With the rapid development of China, Chinese language education is attracting worldwide attention. More and more Chinese immersion programs in the United States have integrated the teaching mode with Chinese characteristics into the original teaching system, so as to create an immersion Chinese classroom with more reasonable planning and more suitable actual situations for students. According to statistics, from 1981 to 2006, there were 25 immersion projects jointly built in the United States. In the past decade, Chinese immersion programs in American primary schools began to develop rapidly, and increased to 213 in 2006-2017. [3]

At the same time, more and more American primary school students are interested in Chinese learning and actively participate in Chinese learning activities. Cornell, the famous scholar, has found that the more students participate in learning activities in school, the higher their scores, and they will show a stronger sense of identity with the school. The desire of students to participate in learning activities is called learning motivation. In recent years, researchers pay more attention to the influence of learning motivation on academic performance, but ignore the influence of learning motivation on learning participation. Learning motivation and learning participation influence each other and are important parts of learning activities.

This study analyzes the relationship among students' motivation, learning participation and academic achievement in a Chinese immersion primary school in Minnesota, the United States, so as to reflect the characteristics of foreign immersion Chinese learning activities, summarize the learning rules with Chinese characteristics suitable for the national conditions of the United States, and then put forward the innovative teaching mode of immersion Chinese.

\section{METHODOLOGY}

\subsection{Learning motivation}

Learning motivation refers to the internal motivation that directly promotes students' learning, and it is also a need to motivate and guide students. Positive learning motivation can help students to increase their interest in learning, clarify their learning goals, and enable them to pursue their own goals persistently. However, negative learning motivation will make students give up their original learning objectives, reduce learning time and learning frequency, and their academic performance will also decline, and finally lose their interest in learning. In education, every teaching activity links the needs to stimulate students' learning motivation. Either the activity 
of reading to promote writing or conversation activities, it needs to be carried out under the conditions of students' interest, otherwise, all the teaching activities are meaningless. Weiner's attribution theory divides the attribution of behavior results into three dimensions: stable or unstable, internal or external, controllable or uncontrollable. The study of second language learners by Noels et al. found that individuals with high endogenous motivation have higher self-efficacy and lower anxiety level. [4] Bandura put forward the theory of self-efficacy. Self-efficacy refers to people's subjective judgment on whether they can complete a task or not. The results of judgment directly affect behavioral motivation. Students' self-efficacy affects their desire, motivation level and academic achievement. [5] It can be seen that learning motivation is an important factor affecting academic performance.

\subsection{Learning engagement}

The theory of student engagement originated from the time on task put forward by Tyler in the 1930s, that is, the more time students devote to learning, the more knowledge they acquire. Kuh put forward Student Engagement Theory in 1991, which emphasizes two aspects: one is the time and energy that students put into effective learning activities; the other is how schools provide support and services for students' learning. [6] Similarly, both for adult students and primary school students, the learning time and experience reflect their willingness to develop their major, which affects their academic performance. It can be seen that students' learning engagement is an important factor affecting academic achievement

According to the levels and ways in which students participate in learning activities, students' engagement can be divided into three dimensions: behavioral engagement, emotional engagement and cognitive engagement. Behavior engagement emphasizes "participation", including extracurricular activities such as academic activities and social practice, which can be expressed as students' behavior, class attendance rate, whether they actively participate in discussions in class; emotional engagement refers to students' positive or negative emotional reactions to teachers, classmates, schools, etc., which can be expressed as the recognition and satisfaction of curriculum, teacher-student relationship. Cognitive engagement is generally related to motivational goals and self-regulation, which can be manifested as flexible handling of various problems, liking difficult tasks, and completing various tasks independently. To sum up, this paper provides the following assumptions:

$\mathrm{H} 1$ : Learning motivation has a direct positive impact on learning engagement;

$\mathrm{H} 2$ : Learning motivation has a direct positive impact on academic achievement;

$\mathrm{H} 3$ : Learning engagement has a direct positive impact on academic achievement.

\subsection{Hypothesis model construction}

Based on the theory of student engagement, learning motivation and related research results, this paper designs a conceptual model of the relationship among students' learning motivation, learning engagement and academic achievement. (see Fig 1)

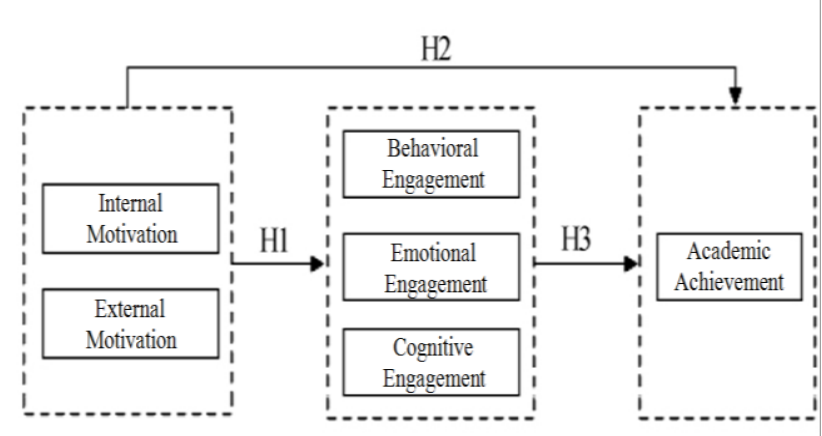

Figure 1. Relationship model of learning motivation, learning engagement and academic achievement

\subsection{Research design}

The theory of student engagement originated from the time on task put forward by Tyler in the 1930s, that is, the more time students devote to learning, the more knowledge they acquire. Similarly, both for adult students and primary school students, the learning time and experience reflect their willingness to develop their major, which affects their academic performance. It can be seen that students learning engagement is an important factor affecting academic achievement.

\subsubsection{Research object}

The subjects were 35 students from two classes of grade three in Lakes International Language Academy, Minnesota. Among them, 12 boys (34.2\%) and 23 girls (65.7\%); 6 students have multilingual family background, accounting for $17.1 \%$; 29 students are native speakers, accounting for $82.8 \%$; the youngest is 8 years old and the oldest is 10 years old.

\subsubsection{Research instruments}

The questionnaire is divided into two parts. The first part is the questionnaire of students' learning motivation, with 10 questions of internal motivation and 7 questions for external motivation; the second part is the questionnaire of students' learning engagement, with 9 questions of behavioral engagement, 7 of emotional engagement and 5 of cognitive engagement. The questionnaire was scored 
with Likert scale 5 ( $1=$ very disagree; $2=$ disagree; $3=$ disagree; $4=$ agree; 5 = strongly agree).

The measurement scale of learning motivation mainly refers to the Learning Motivation Scale compiled by Amabile and Hill. Chi Liping and Xin Ziqiang tested the reliability and validity of the scale in 2006, and the Cronbach $\alpha$ coefficients were 0.75 (endogenous motivation subscale) and 0.70 (exogenous motivation subscale) respectively. On this basis, the questions of learning motivation are modified according to the research questions: five questions of internal motivation and five questions of external motivation are obtained.

\subsubsection{Data collection and analysis}

The questionnaire is conducted by the teachers during the class break. Before the students' answer, teacher introduces the purpose and method of the survey first. The questionnaire is presented in English, and the teacher reads and explains the questions which students can't understand. In this survey, 40 questionnaires were collected and 35 were valid (the effective rate was $87.5 \%$ ). The author uses the data analysis software SPSS 20.0 to make a descriptive analysis of the data, so as to make statistics on the basic situation of the students' learning motivation and learning engagement, and then, factor analysis is conducted to explore the main factors influencing the subjects' motivation, and finally verifies the relationship among students' learning motivation, learning engagement and academic achievement.

\section{RESULTS AND DISCUSSION}

\subsection{Validity analysis of the questionnaire}

According to the theory of factor analysis, if the correlation coefficient of factors is too large, it means that there is overlap between factors, which should be eliminated or selected; otherwise, if the correlation coefficient is too small, it means that the factor does not belong to the content of psychological characteristics to be studied and should be dealt with. In order to test the reliability and validity of the experiment, the psychometrist Tuker proposed that the correlation coefficient between the items should be between 0.10 and 0.60 . The factors in this range not only can meet the medium degree of correlation, reflect the same psychological characteristics, but also be different from other factors and reflect the research content from different angles. These research structure analysis results of each dimension are shown in Table 1.

According to the statistical data in Table 1 , there is a moderate degree of correlation between the dimensions. The structure of the questionnaire is basically consistent with the structure of the ideal concept, and the construct of the questionnaire is valid. At the same time, it also shows that there is a very close relationship between learning motivation and learning engagement.

Table 1 shows the internal motivation and behavior engagement $(r=0.576, P<0.05)$, emotional engagement $(r$ $=0.458, \mathrm{P}<0.05)$, cognitive engagement $(\mathrm{r}=0.657, \mathrm{P}<$ $0.05)$, It can be seen that students' learning motivation caused by individual internal needs can positively affect students' interest in Chinese learning and improve their attitude. At the same time, students' external motivation was significantly positively correlated with their behavior engagement $(r=0.465, P<0.05)$, emotional engagement ( $r$ $=0.447, \mathrm{P}<0.05)$, and cognitive engagement $(\mathrm{r}=0.443, \mathrm{P}$ $<0.05)$. It shows that the motivation induced by external stimulation closely related to learning activities can also provides students with further interest in Chinese learning. The above statistical data shows that there is a significant positive correlation between students' learning motivation and learning engagement, which conforms to the first hypothesis of the study.

Table 1. Correlation analysis of learning motivation and learning engagement

\begin{tabular}{|c|c|c|c|c|c|}
\hline Dimensions & IM & EM & BE & EE & CE \\
\hline $\begin{array}{c}\text { Internal } \\
\text { Motivation }\end{array}$ & 1 & & & & \\
\hline $\begin{array}{c}\text { External } \\
\text { Motivation }\end{array}$ & $0.442 * *$ & 1 & & & \\
\hline $\begin{array}{c}\text { Behavioral } \\
\text { Engagement }\end{array}$ & $0.576 * *$ & $0.465 * *$ & 1 & & \\
\hline $\begin{array}{c}\text { Emotional } \\
\text { Engagement }\end{array}$ & $0.458 * *$ & $0.447 * *$ & $0.529 * *$ & 1 & \\
\hline $\begin{array}{c}\text { Cognitive } \\
\text { Engagement }\end{array}$ & $0.657 * *$ & $0.443 * *$ & $0.565 * *$ & $0.612 * *$ & 1 \\
\hline
\end{tabular}

Table 2. General situation of students' learning motivation, learning participation and academic achievement $(\mathrm{N}=35)$

\begin{tabular}{|l|l|l|}
\hline Dimensions & $\mathbf{N}$ & $\mathbf{M} \pm$ SD \\
\hline $\begin{array}{l}\text { Internal } \\
\text { Motivation }\end{array}$ & 35 & $3.73 \pm 1.01$ \\
\hline $\begin{array}{l}\text { External } \\
\text { Motivation }\end{array}$ & 35 & $3.57 \pm 0.89$ \\
\hline $\begin{array}{l}\text { Behavioral } \\
\text { Engagement }\end{array}$ & 35 & $3.29 \pm 0.94$ \\
\hline $\begin{array}{l}\text { Emotional } \\
\text { Engagement }\end{array}$ & 35 & $3.54 \pm 0.95$ \\
\hline $\begin{array}{l}\text { Cognitive } \\
\text { Engagement }\end{array}$ & 35 & $3.46 \pm 0.91$ \\
\hline Academic Achievement & 35 & $3.57 \pm 1.38$ \\
\hline
\end{tabular}

The average and standard deviation of the six variables of internal motivation, external motivation, behavioral engagement, emotional engagement, cognitive engagement and academic achievement are shown in table 2. From the mean and standard deviation, we can see that in the sample data, students have high level of intrinsic motivation, 
external motivation, emotional participation and academic achievement. The average scores of these four dimensions of learning factors are higher than the overall average score, while behavioral engagement and cognitive engagement have not reached the average score.

\subsection{Analysis of students' academic achievements}

In order to make academic achievement more intuitive and better compared with learning motivation, learning engagement and other factors, students' academic achievement is divided into five stages. The segmentation of students' academic achievement is shown in table 3 .

The total number of students is 35 , the highest score is 25 , the lowest score is 5, and the average score is 16.89 . Therefore, in accordance with Likert five level scale, and based on the principle of equidistance, the score segments are divided into five segments in the same distance: 1 point for "fail" and 5-9 points for scores; 2 points for "pass" points for 9-13 points; 3 points for "medium", with 13-17 points; 4 points for "good", with 17-21 points; 5 points for "excellent", with 21-25 points. The average score of students is 3.57 . The frequency of students who get 1-5 points is $4,5,4,11,11$.

Table 3. Segmentation ratio of students' academic achievement

\begin{tabular}{|c|c|c|}
\hline & Fraction & Frequency \\
\hline 1 Fail & {$[5,9)$} & 4 \\
\hline 2 Pass & {$[9,13)$} & 5 \\
\hline 3 Medium & {$[13,17)$} & 4 \\
\hline 4 Good & {$[17,21)$} & 11 \\
\hline 5 Excellent & {$[21,25)$} & 11 \\
\hline & Total & 35 \\
\hline Missing & System & 12 \\
\hline
\end{tabular}

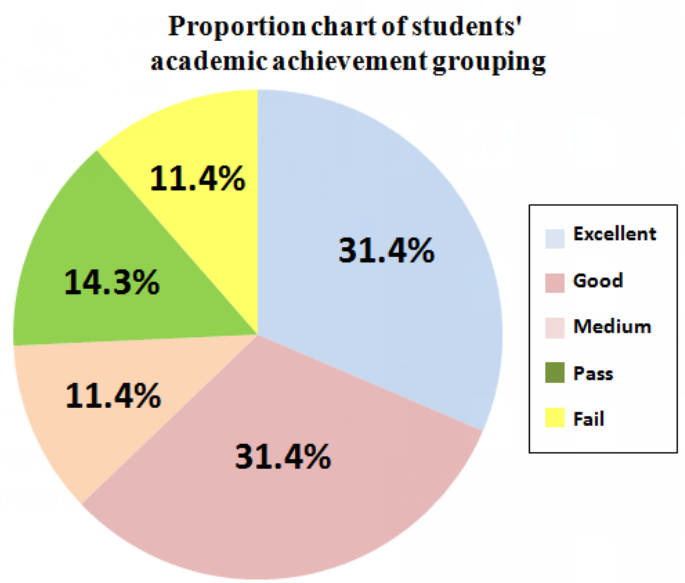

Figure 2. Proportion of students' academic achievement grouping
As shown in the proportion chart of students' academic achievement grouping, the main scores are 4 points and 5 points. The number of students in both groups is 11 , accounting for $31.4 \%$ respectively. Therefore, more than half of the students can obtain 4 points or above, and the overall academic level of students is at a higher stage. However, the number of students who failed also accounted for $11.4 \%$, and there was still room for improvement in students' scores.

\subsection{Variance analysis}

In order to make academic achievement more intuitive and better compared with learning motivation, learning engagement and other factors, students' academic achievement is divided into five stages. The segmentation of students' academic achievement is shown in Table 4 .

Table 4. Analysis of differences in learning motivation of students of different genders

\begin{tabular}{|c|c|c|c|c|}
\hline & \multicolumn{2}{|c|}{$\begin{array}{c}\text { Internal } \\
\text { Motivation }\end{array}$} & \multicolumn{2}{c|}{$\begin{array}{c}\text { External } \\
\text { Motivation }\end{array}$} \\
\hline & $\mathbf{M} \pm$ SD & T & M \pm SD & T \\
\hline Male & $3.00 \pm 1.21$ & $-2.24^{*}$ & $3.25 \pm 1.06$ & $-2.37^{*}$ \\
\hline Female & $3.73 \pm 0.75$ & & $3.96 \pm 0.71$ & \\
\hline
\end{tabular}

Table 4 shows that there are differences in intrinsic motivation $(\mathrm{t}=-2.24, \mathrm{P}<0.05)$ and extrinsic motivation $(\mathrm{t}$ $=-2.37, \mathrm{P}<0.05)$ between male and female students, and female students' overall score of learning motivation is higher. After analyzing the scores of specific items of intrinsic motivation, both male and female students are positive when they are studying problems and learning what they are interested in. However, female students are more inclined to think independently and solve difficult problems on their own. After analyzing the items of extrinsic motivation, it is found that female students are more likely to be interested in learning when they are encouraged or praised, while male students are more encouraged by positive learning outcomes.

The statistical data in Table 5 show that there are differences between male and female students in behavioral engagement $(\mathrm{t}=-2.18, \mathrm{P}<0.05)$, emotional engagement $(\mathrm{t}=-4.53, \mathrm{P}<0.01)$ and cognitive engagement $(\mathrm{t}=-2.10, \mathrm{P}<0.05)$, among which there is significant difference between male and female students in emotional engagement. The survey shows that male and female students get average scores in class participation, but girls get more scores than boys in homework completion after class. Therefore, the difference in behavior engagement is caused by the gap in curriculum resources. The limited curriculum resources of the school can't meet the male students' pursuit of fresh knowledge, so the male students' score on this item is lower. According to the survey data of cognitive engagement, female students tend to think independently and fit in with their internal motivation. 
Table 5. Analysis of the differences in learning engagement of students of different genders

\begin{tabular}{|c|c|c|c|c|c|c|}
\hline & \multicolumn{2}{|c|}{ Behavioral Engagement } & \multicolumn{2}{c|}{ Emotional Engagement } & \multicolumn{2}{c|}{ Cognitive Engagement } \\
\hline & $\boldsymbol{M} \pm \boldsymbol{S} \boldsymbol{D}$ & $\boldsymbol{T}$ & $\boldsymbol{M} \pm \boldsymbol{S D}$ & $\boldsymbol{T}$ & $\boldsymbol{M} \pm \boldsymbol{S D}$ & $\boldsymbol{T}$ \\
\hline $\begin{array}{c}\text { Multilingual } \\
\text { Family }\end{array}$ & $3.67 \pm 1.03$ & $1.28^{*}$ & $3.83 \pm 1.47$ & 0.92 & $2.67 \pm 1.03$ & $-2.82 * *$ \\
\hline $\begin{array}{c}\text { Monolingual } \\
\text { Family }\end{array}$ & $3.10 \pm 0.98$ & & $3.48 \pm 0.69$ & & $3.69 \pm 0.76$ & \\
\hline
\end{tabular}

Table 6. Variance analysis of learning motivation between monolingual and multilingual students

\begin{tabular}{|c|c|c|c|c|}
\hline & \multicolumn{2}{|c|}{$\begin{array}{c}\text { Internal } \\
\text { Motivation }\end{array}$} & \multicolumn{2}{c|}{$\begin{array}{c}\text { External } \\
\text { Motivation }\end{array}$} \\
\hline & $\mathbf{M} \pm$ SD & $\mathbf{T}$ & $\mathbf{M} \pm$ SD & $\mathbf{T}$ \\
\hline $\begin{array}{c}\text { Multilingual } \\
\text { Family }\end{array}$ & $3.67 \pm 1.37$ & 0.49 & $\begin{array}{c}2.83 \pm 0 . \\
98\end{array}$ & $-2.49 *$ \\
\hline $\begin{array}{c}\text { Monolingual } \\
\text { Family }\end{array}$ & $3.41 \pm 1.09$ & & $\begin{array}{c}3.89 \pm 0 . \\
77\end{array}$ & \\
\hline
\end{tabular}

The statistical data in Table 6 show that there is no difference in internal motivation $(\mathrm{t}=0.49, \mathrm{P}>0.05)$ between monolingual and multilingual families, while there is a difference in external motivation $(\mathrm{t}=-2.49, \mathrm{P}<$
0.05). The results show that students from monolingual families are more likely to be driven by curiosity and to devote themselves to learning activities. The statistical data in Table 7 show that there are differences in behavioral engagement $(\mathrm{t}=1.28, \mathrm{P}<0.05)$ between monolingual and multilingual families, no difference in emotional engagement $(t=0.92, \mathrm{P}>0.05)$, but significant difference in cognitive engagement $(\mathrm{t}=-2.82, \mathrm{P}<0.01)$. The difference in students' behavior engagement mainly comes from the fact that students from monolingual families learn by reading multiple related textbooks, while students from multilingual families tend to use the same textbook. Through the analysis of significant differences in students cognitive engagement items, it is found that students from monolingual families often summarize their own learning methods and habits to achieve better learning results.

Table 7. Variance analysis of learning engagement between monolingual and multilingual students

\begin{tabular}{|c|c|c|c|c|c|c|}
\hline & \multicolumn{2}{|c|}{ Behavioral Engagement } & \multicolumn{2}{|c|}{ Emotional Engagement } & \multicolumn{2}{|c|}{ Cognitive Engagement } \\
\hline & $\mathbf{M} \pm$ SD & $\mathbf{T}$ & M \pm SD & $\mathbf{T}$ & $\mathbf{M} \pm$ SD & $\mathbf{T}$ \\
\hline Male & $2.83 \pm 1.11$ & $-2.18 *$ & $2.92 \pm 0.90$ & $-4.53 * *$ & $3.08 \pm 0.99$ & $-2.10 *$ \\
\hline Female & $3.57 \pm 0.84$ & & $4.00 \pm 0.52$ & & $3.78 \pm 0.90$ & \\
\hline
\end{tabular}

and also makes students have emotional identity and inner

\section{CONCLUSION}

From the perspective of students' experience, this study establishes a model of the relationship among students' learning motivation, learning engagement and academic achievement. Through questionnaire, descriptive statistics, difference analysis (T-test) and correlation analysis are used to quantitatively study the basic situation of learning motivation and learning engagement of Chinese immersion primary school students in Minnesota, USA. The conclusion and enlightenment are as follows:

First, increase the interaction between students' internal motivation and learning engagement. According to the data of this study, students' internal motivation has a direct positive impact on learning engagement. The survey results clearly verify that improving students' internal learning motivation is the fundamental motivation and effective source of students' effective participation. Therefore, students can cultivate their own learning habits, summarize effective learning rules, and cultivate the ability to solve problems independently.

Second, enhance the influence of external motivation on learning engagement. External motivation has a certain impact on the surface behavior of students' participation, cognition to learning activities. In the case of positive learning guidance, students can also stimulate their interest in learning. Therefore, teachers should encourage students, improve teaching environment and enrich teaching resources.

Third, make full use of the external conditions of students and transform them into new learning motivation. Learning motivation and learning participation do not have a direct positive impact on academic achievement, but through the variance analysis, it can be seen that students' external conditions still affect students' academic achievement. One of the characteristics of immersion schools is the diversity of student categories. Students from all over the world are integrated because they can communicate with the same language. The proportion of multilingual family background in the survey class is higher than that in ordinary schools.

This study analyzes the students' motivation and engagement in Chinese immersion primary school students in Minnesota through the multi-dimensional quantitative questionnaire and the construction of the relationship model. The main purpose of this study is to understand the teaching and learning status of immersion projects, to put forward new teaching ideas, new ideas for learning, and to elaborate on the overall improvement of immersion Chinese projects. Through this study, the author hopes that 
not only Chinese immersion schools in the United States, but also Confucius Institutes from China and international schools around the world can actively pay attention to the improvement of students' ability of this special project, and provide them with innovative development platform through multiple channels combined with excellent educational resources from many countries. At the same time, the author hopes that through this investigation, more scholars will pay attention to immersion teaching programs in Chinese, and further explore it from different perspectives and theoretical levels, and promote the development of international Chinese education in different regions.

\section{REFERENCES}

[1] Richards, Jack \& Richard Schmidt. Longman Dictionary of Language Teaching and Applied Linguistics. Harlow, U.K: Longman, 2010.
[2] R. K. Johnson, M. Swain. Immersion Education: International Perspectives, Cambridge: Cambridge University Press, 1997.

[3] Yonghua Cui. On the development of vocabulary syllabus for primary school immersion Chinese Textbook. vol. 2, pp 48-56, 2014. (In Chinese.)

[4] Noels K A, Clement R, and Pelletier L G. Intrinsic, extrinsic, and integrative orientations of French Canadian learners of English. The Canadian Modern Language Review. vol. 57, no. 3, pp 424-442, 2001.

[5] Bandura A. Self-efficacy in Changing Societies. New York: Cambridge University Press, 1995.

[6] Kuh G D. Assessing What Really Matters to Student Learning Change: Inside the National Survey of Student Engagement. vol. 33, no. 3, pp 10-17, 2001. 